International Journal of Applied Linguistics \& English Literature

ISSN 2200-3592 (Print), ISSN 2200-3452 (Online)

Vol. 1 No. 7; November 2012 [Special Issue on Applied Linguistics]

\title{
Intragroup Conflicts during Collaborative Writing in an ESL/EFL Preparatory Programme
}

\author{
Santini Pathinathan \\ (Master candidate) \\ Department of English \\ Faculty of Modern Languages and Communication \\ Universiti Putra Malaysia \\ 43400 UPM Serdang, Selangor, Malaysia \\ Yong Mei Fung (Corresponding author) \\ Department of English \\ Faculty of Modern Languages and Communication \\ Universiti Putra Malaysia \\ 43400 UPM Serdang, Selangor, Malaysia \\ Tel: +603-89468679 E-mail: yong@fbmk.upm.edu.my
}

Received: 20-10- 2012

doi:10.7575/ijalel.v.1n.7p.8
Accepted: 22-11- 2012

Published: 25-11- 2012

\begin{abstract}
This paper seeks to investigate the types of conflicts that occur during collaborative writing among a group of ESL/EFL upper intermediate students in a preparatory programme. It also examines how these conflicts are resolved among the group members. A group consisting of four students was chosen for this study. Audio and video-recordings of collaborative sessions, semi-structured interviews and students' journal were used in the data collection process. The results of this qualitative study showed that there were two prominent types of conflicts that occurred during the collaboration, namely, substantive conflict and affective conflict. Substantive conflict was found to be useful as the group was able to voice disagreements and consider alternative ideas. However, there was more evidence of affective conflict where the group had misunderstandings and differences due to personal views about group members. The study shows that the success of collaborative writing depends very much on how conflict is handled and resolved among the members.
\end{abstract}

Keywords: collaborative writing, substantive conflict, affective conflict, argumentative essay, ESL/EFL learners

\section{Introduction}

Collaborative writing is "the production of a single text by co-authors or group authors" (Ede \& Lunsford, 1985, p.14). Much attention has been bestowed on collaborative writing since early 1970's when Bruffee (1973) argued that students produced better work when they write in groups. Language instructors have been using collaborative writing at the tertiary levels (Lee, 2011; Luca \& Tarricone, 2001; Storch, 2002, 2005, 2011; Yong $2010,2011)$. This is because learning to collaborate is important to develop team spirit which is applicable in work places that often involve team projects (Strauss, 2001).

Although there have been recommendations for the use of collaborative writing (Barron, 2003; Hilgers, 1987; Lee, 2011; Tocalli-Beller, 2003), writing instructors have limited knowledge about what actually takes place during collaboration. Students are rarely provided the opportunity to write collaboratively as teachers and students tend to perceive that the practice is time-consuming (Krause, 2007). Some writing instructors also claim that it is not rational because not everyone will be able to work with others who have different opinions and conflict may occur (Stewart, 1988). 
International Journal of Applied Linguistics \& English Literature

ISSN 2200-3592 (Print), ISSN 2200-3452 (Online)

Vol. 1 No. 7; November 2012 [Special Issue on Applied Linguistics]

The significance of collaborative writing as a way to improve language and writing in second language learning is drawn from a sociocultural perspective (Storch, 2005; Villamil \& de Guerrero, 1996, 1998). Vygotsky (1978) claims that social interaction between a novice and a competent peer mediates the learning process. It is important that socially rich situation be made available to learners for better cognitive development. Bruner (1975) points out that scaffolding is important as a representation of assistance during the collaboration when shifting towards the potential level of cognitive development from the actual level in the zone of proximal development. In order for scaffolding to be effective, the amount of help that is needed by the learner should be given only when needed, and it is achieved through dialogue (Aljaafreh \& Lantolf, 1994).

Collaborative writing is a social process where learners may face conflict and they negotiate to reach consensus (Derry, 1992). Shantz (1987) states that conflict is a form of argument between two people or more that indicate disagreement regarding their objective, behaviour, point of view or opinion. Although conflict may enhance learning in a collaborative group, its threat needs to be taken into account, so that it can be beneficial to the learner (Tocalli-Beller, 2003). When the members' ideas are in conflict, Trimbur (1989) calls this situation as "intellectual negotiation" (cited in Burnett, 1993).

Putnam (1986) has identified three types of conflicts, namely, affective conflict, procedural conflict and substantive conflict. Affective conflict focuses on the collaborators' personality instead of the procedure or the task, whereas procedural conflict focuses on everything from agreeing on where to meet at an expected time to voicing their opinion and solving disagreements. Substantive conflict, on the other hand, focuses on taking into account the alternatives and voicing disagreement. Substantive conflict puts off consensus, thus, allowing possibilities to surface. Substantive conflict may also be termed as "cognitive conflict", "task or issue-oriented conflict" (Eisenhardt, Kahwajy \& Bourgeois, 1997).

Dale's (1994) study on ninth-grade students, who wrote argumentative writing collaboratively, revealed that the model group was more engaged with each other's words and ideas than the typical group and the problem group. The problem group faced conflict and experienced non-productive discussion due to issues of power where one member dominated the group. Conflict may also occur due to the differences in culture. Carson and Nelson (1996) investigated Chinese students' interaction styles and reactions to peer response groups in ESL composition and discovered that Chinese students considered it crucial to maintain the harmony of the group. It affected the way the students interacted in their group discussions. They were very careful when giving comments so that there would not be any conflicts within the group. This is in line with Hofstede's (1980) cultural dimension where the Chinese culture values group harmony.

In documenting her own learning experience in a graduate course, Tocalli-Beller (2003) examined whether conflict in a collaborative group enhances learning. She found the occurrence of cognitive conflict provided opportunity towards valuable learning. Different views and alternatives were evaluated as long as group members were comfortable with cognitive conflict. However, she also found that affective conflict was detrimental towards group function. Another classroom based study exploring the nature of collaborative writing of three cases in a tertiary context was carried out by Yong $(2010,2011)$. Her findings showed that it is important for group members to be familiar with one another to ensure group cohesion. As tasks became more complex, conflict also became more intense because group members have to resolve conflicting views. In addition, authoritative and dominant behaviour may intimidate group members, hence, preventing productive discussion.

Lee (2011) who highlighted that there was not much research conducted especially in the ESL context carried out a study to describe the decision making processes during collaborative writing of an argumentative essay. Her study involved six college freshmen as participants who formed two groups. She found that the participants spent more time forming sentences from their ideas than planning. Lee also found longer turns for the category of voicing explicit disagreement and conflict due to the participants' low proficiency in English. Her participants also faced conflict due to their lack of knowledge of writing.

\subsection{Research Objectives}

The two-fold objectives of this study are: a) to find out what kinds of conflicts occur during collaborative writing among ESL/EFL preparatory learners and $b$ ) how the learners resolve the conflict. Findings from the study will provide insights into collaboration processes and add to the existing pool of knowledge on conflict during collaboration. 
International Journal of Applied Linguistics \& English Literature

ISSN 2200-3592 (Print), ISSN 2200-3452 (Online)

Vol. 1 No. 7; November 2012 [Special Issue on Applied Linguistics]

\section{Methodology}

\subsection{Participants}

The study was conducted in an English Language Centre (ELC) at a private institution of higher learning in Malaysia. The Language Centre offers English Improvement Program (EIP) such as Listening and Speaking, Reading, and Grammar and Writing. The students who enrol in this private institute have to sit for an English Placement Test one week before the semester begins. The English Placement Test is also used to determine the students' proficiency level.

Data were collected from three groups in an intact classroom from EIP 140 Upper Intermediate level, which is a Grammar and Writing class. All the students in the course participated in three collaborative writing sessions over seven weeks. During the collaboration, they discussed, planned, wrote, and edited three argumentative essays. The students were assigned to form groups consisting of four members in a group. They were given a choice between choosing their own group members or assigned randomly by the instructor cum researcher. The three cases volunteered to participate in the study. Prior to data collection, a video was shown to the class to illustrate how collaboration should be carried out.

This paper, which is part of a larger qualitative case study, only presents one case for in-depth analysis. The participants' profile is presented in Table 1. Their actual names have been changed.

Table 1 Profile of Participants

\begin{tabular}{llll}
\hline Name & Gender & Nationality & Age \\
\hline Dee & Female & Indonesia & 17 \\
Kamal & Male & The U.A.E & 19 \\
Liang & Male & China & 21 \\
Mia & Female & Indonesia & 25 \\
\hline
\end{tabular}

Mia and Dee were very close to each other. Kamal was a likeable person, therefore, he could integrate well with this group. Liang was the out-group member because his thick Chinese accent made it difficult for his group members to understand and to relate to him. Mia, the oldest among the four members, was the scribe for all three tasks and she played a more dominant role as she felt that she was more knowledgeable. Besides Mia, Kamal was also domineering. His stay in Malaysia for the past two years before enrolling in the English Improvement Programme enables him to speak Malay language quite well.

\subsection{Research Instruments}

Argumentative writing was chosen because this mode of writing generates a lot of cognitive processes which trigger discussions. Group interactions during the collaboration were audio and video-recorded. The participants also wrote their experiences and perceptions on collaboration in journals after each session. They were also interviewed individually after each collaborative session. The audio-recordings and interviews were transcribed verbatim.

Audio transcriptions were analysed qualitatively to identify the conflict that occurred during the group interactions. The transcriptions of group discussion were segmented into episodes. Each episode represents a topic of discussion. Critical incidents were selected for in-depth analysis. The interview responses and journal entries were categorised into major themes and were used to triangulate the findings from the transcriptions of the group discussions.

\section{Results and Discussion}

\section{a) Substantive Conflict}

Substantive conflict can be productive in collaborative writing because it provides more time and opportunity for the group to express disagreement and explore alternative ideas (Burnett, 1993). During the first collaborative task, the group had to deliberate whether to take the stance to agree or disagree with the topic on "Gay marriage should not be legalised." Excerpt 1 shows the negotiation process to reach a decision. 
International Journal of Applied Linguistics \& English Literature

ISSN 2200-3592 (Print), ISSN 2200-3452 (Online)

Vol. 1 No. 7; November 2012 [Special Issue on Applied Linguistics]

\section{Excerpt 1}

28. L: Agree, yes, err, first I think the gay marriage is emm is natural because gay also is people, some relationships as emm gay it also is err...arr people become more and more err... more and more what? Emm more and more clever

29. M: Huh?!

30. L: More and more clever because it err belong to natural I think, it belong to natural, nature

31. M: nature

32. K: nature

33. L: yes

Liang disagreed that gay marriage should not be legalised. He justified by mentioning that gay marriage is natural. This may be due to the fact that gay relationship is quite common in China; therefore, Liang assumed that it is acceptable. However, Mia expressed disgust and shock when Liang mentioned that gay people are more clever. Kamal, on the other hand, expressed his indifference towards gays as seen in line 87 below.

87. K: What is the problem if man get with man? I don't care, I don't pay for them money

88. D: It err... don't you feel, don't you feel disgusting about that?

89. K: Okay, I feel disgusting but I don't pay for them money, I don't care about them. They do

Whatever they want...

90. K: So write introduction

91. M: Write introduction, what you can write in introduction? If we had no-

92. D: What we cannot, if we not decided, decided about agree or disagree, with we want to write?

93. M: You agree

94. K: The first thing introduction

95. D: Yes

96. K: Agree. If we agree, we write three paragraph about agree, so-

Kamal was not interested on matters which did not concern him. The group had to reach an agreement on their stand before they could draft their essay. There was a slight affective conflict between Mia and Kamal where Mia snapped back at Kamal for rushing her to write the introduction before a proper decision was made (line 91). Dee interrupted Mia and explained to Kamal that they could not write if the decision was not made. She was more polite and affiliative compared to Mia who seemed to be unhappy with the authoritative manner in which Kamal spoke.

Mia also wrote in her journal that she was annoyed when Kamal and Liang disagreed with the topic while she and Dee took the opposite stand. Mia felt that the male members were not serious because in her opinion gay marriage is wrong and she could not understand why they wanted to support gay marriage.

As they continued to deliberate whether to agree or disagree, Kamal pointed out that they would have more points to write if they disagree with the topic. He also questioned the females' rationale of their opinions. Dee and Mia provided experiences from their own countries and moral views to justify their arguments. Then, Dee asked the males to justify theirs.

\section{Excerpt 2}

119. K: You have information about why you agree?

120. D: Yes, because in my country, many arr... more of the gay people cannot go out because many people, many people err... disgusting with them err... because there are two men, two men

121. M: Opposite their... religion I think, who can be

122. D: Mmm two men and they walk together or kiss or something like that ( $\mathrm{L}$ and $\mathrm{D}$ laugh)

$\ldots$

133. D: Ah... the reason, the reason about disagree, why?

134. L: Err... because I think people can err get some suitable life for example so they choose err this life, in their opinion, err it's right, it's true err... it's a beautiful life for them, so I disagree err gay marriage shouldn't be emmm legalised. Yes.

135. M: and then?

136. K: Because you don't care about them, you don't pay anything for them, so disagree, disagree. They do whatever they want

137. D: but 
International Journal of Applied Linguistics \& English Literature

ISSN 2200-3592 (Print), ISSN 2200-3452 (Online)

Vol. 1 No. 7; November 2012 [Special Issue on Applied Linguistics]

138. K: Disgusting for you, but... (all laugh)

139. K: For some people, so, disgusting for me but they do whatever they want. Disagree lah...

Liang explained that people have the rights to choose the way they want to live. Although gay marriage may be disgusting for Dee and Mia, it is a choice for others. Mia stood firm with her decision while Kamal was noncommittal and found it easier to just disagree with the topic. Liang also held firm to his stand. There was conflict at this point due to disagreements as each member felt that his or her idea was better than the others.

145. M: My reason about the religion

146. L: and you think my reason have some mistakes?

147. D: No

148. M: Only you... disagree

Liang questioned Mia if she considered his reasons to be flawed. Dee replied no although she did not share his viewpoint. She tried to avoid conflict. Mia pointed out to Liang that he was the only member in the group who held an opposite view. She was dominant and wanted the others to listen and to accept her stand. Nevertheless, Mia finally consented to the group decision because she realised that time would be wasted if the group kept arguing. As mentioned in her interview responses:

I thought it was a waste of time to keep asking them to agree with the topic. I don't understand what is wrong with them. I think gay marriage is very disgusting but they say they don't care. How can you say you don't care? But I just wanted to finish the essay, so I ask them to give the points since they agree with gay marriage.

Since Mia could not convince her male members to accept her view, she gave up persuading them and accepted their opinion in order to complete the task. She resolved the conflicting viewpoints by asking the male members to provide ideas to substantiate their argument.

When they began to write the introduction, Mia wanted to know whether to mention gays as gay partners or gay couples or use other reference. There were deliberations of word choices to find the most suitable words.

\section{Excerpt 3}

433. M: Gay couple yeah what they call for the gay couple?

434. D: partner

435. M: not partner... gay, we can we

436. L: ohh partner

437. M: gay, gay what?

438. D: partner

439. M: gay partner? (D laughs)

440. M: Nowadays we can find many

441. D: with his partner

442. M: I think

443. K: What?

444. D: The gay couple then partner

445. M: emm nowadays...

446. K: friend

447. D: friend

448. K: ah

449. L: Gay friend, are you sure?

450. K: They like each other

451. L: yes

452. M: In every country, we can find, yes?

453. L: Yes

454. M: Gay couple or gay partner?

455. D: Gay partner, gay couple or gay friend?

520. K: It's ok, many gays

521. L: live together

522. M: and they living together without marriage is it?

523. L: oh...

524. M: yeah 


\section{International Journal of Applied Linguistics \& English Literature}

ISSN 2200-3592 (Print), ISSN 2200-3452 (Online)

Vol. 1 No. 7; November 2012 [Special Issue on Applied Linguistics]

The group deliberated on word choices. After spending about 10 minutes testing out ideas to describe gay couple, Kamal suggested that they just use the word gay on its own and everyone consented. This shows that when the group delayed decision making, they tend to consider other alternatives. In this case, the group managed to consider three different words gay partners, gay couple, and gay friend but due to time constraint, they decided to just use the word gay.

The substantive conflict this group faced made them produce a more interesting essay. They faced conflict in deciding the stand to take which created opportunities for negotiation before they reached a decision. Putting off consensus also made them tried out alternatives until they found an appropriate word choice. The members benefitted from the substantive conflict as they engaged in constructive discussion of ideas (Jehn, 1995). However, the members also experienced affective conflict which is considered to be detrimental to the group, as demonstrated in the next section.

\section{b) Affective Conflict}

In-group/out-group

Affective conflict focuses on the collaborators' personality (Putnam, 1986). The next excerpt is taken from Task 1 as the group was brainstorming to write the introduction paragraph. This excerpt shows an in-group/out-group situation among the members where Liang was the out-group member. This excerpt also reveals how Liang's face is affected (losing face). Face issue happens in a situation when the interaction in a social setting challenges one's reputation, status, standing or when one is humiliated (Liao, 2007). The excerpt also highlights a strategy that was frequently used by this group that is writing one's idea down on paper.

\section{Excerpt 4}

598. L: populacy, cy
599. M: popular?
600. D: popular things things

601. L: things

602. M: thing

603. L: thing $\mathrm{mm} .$. yes... and then

(M and D laugh)

604. K: Chinese accent. K. Can you write it?

605. L: This gay marriage

606. K: Can you write it? What do you say?

607. M: Yeah, because I cannot understand.

608. D: yes

609. L: ok

Due to Liang's accent, the others could not really understand what he was trying to say. He pronounced thing as sing. Only Dee was able to understand what Liang was saying, but the rest of the group members wanted him to jot his idea down on paper. This illustrates an in-group/out-group situation where members who were able to understand each other got along better while Liang felt disconnected from the group. He felt a little embarrassed when Kamal and Mia mentioned that they could not understand him. After the incident, Liang resorted to limiting his responses to either "yes", "no", or "okay". This went on for some time until the group positively acknowledged his idea. This occurrence is in line with Liao (2007) who claims that when someone loses face, he or she might react in a way to restore his or her face. Whether their relationship gets better or worse depends on the responses of the people who interact with them. When Liang received positive acknowledgement about his written idea, it encouraged him to participate more.

Liang's journal entry showed that he felt sad and lacked the sense of belonging in the group. He wrote:

I felt like my group members were very close with each other because they can speak English better, but my English is not good, so I felt alone and maybe they think I bring trouble to them.

However, Mia mentioned in her journal that although Liang's accent was difficult to be understood, she wished that he spoke more so that the group could know him better. This shows the group did not address the issue explicitly but chose to keep feelings to themselves which in turn could have contributed to the miscommunication. 
International Journal of Applied Linguistics \& English Literature

ISSN 2200-3592 (Print), ISSN 2200-3452 (Online)

Vol. 1 No. 7; November 2012 [Special Issue on Applied Linguistics]

Doubt over other's capability

During their second collaborative writing session, the students were required to write an essay entitled "Alcohol should be restricted to those who are 21 years old and older." Kamal and Mia again had some conflict. While the group was engaged in the prewriting stage of supporting paragraph one, Mia refused to accept Kamal's sentence structure to explain their supporting detail. Their first supporting paragraph was about young people lacking self-control. Kamal then suggested an idea for supporting paragraph two about young people not having responsibility. Mia rephrased Kamal's sentence structure. She considered Kamal to be a playful person; therefore, she did not take his suggestions seriously. She wrote her own sentence which was not grammatical. This caused Kamal to question why the sentence was incorrect and different from what he suggested earlier. Amason (1996) states that doubt or judgement of a person's capability may be considered as a personal condemnation or a way to develop one's status at another person's expense.

\section{Excerpt 5}

465. K: They don't have responsibility

466. M: they

467. D: themselves

468. L: yes

469. M: Yeah, they have no, they cannot respon-they have no responsibility they're yeah, they a what? (All laugh)

470. M: I forgot, below twenty one years old they cannot

471. K: Okay

472. M: responsibility, they have no-

473. K: What? What? What? They

474. L: cannot

475. K: They don't have responsibility

476. M: have not, have not

477. L: Yes, they don't have

478. M: They don't have

479. K: Yes, not they cannot (all laugh)

...

494. D: They cannot do, have not responsibility

495. M: They have, not don't have like this

496. D: Oh

Although Kamal had clearly told Mia that the structure should be they don't have responsibility (line 475), she did not accept his suggestion. She changed the sentence to they have not responsibility as she explained to Dee (line 495). This made Kamal to question her word choice.

500. K: How come? They need do have not? They don't have

501. L: yes

502. M: yeah, this?

503. K: ah

504. M: like this

505. D: They don't have]

506. K: Ah, so this cross out

507. D: So, they don't have not (laughs)

508. M: Actually, I want to say have not

509. K: It's ok... about the education, the third one?

Liang and Dee supported Kamal's suggestion. However, Mia tried to explain why she changed the structure. Since Mia was adamant, Kamal decided to end the contention by changing the topic to talk about the third supporting paragraph. This situation is similar to what Tocalli-Beller (2003) reported in her study when she confronted her group about wanting to speak more, the male member quickly ended the discussion by changing the topic. Kamal was displeased with Mia for changing his sentence structure. During the interview, he mentioned that he found Mia to be too picky and bossy during the collaborative writing sessions. However, he also mentioned that he would not have confronted her if the sentence was correct. He was annoyed that she refused to accept his suggestion even though her structure was ungrammatical. However, he did not want to 
aggravate the situation because the most important part of the collaborative session for him was to produce their essay. From that point onwards, Kamal just agreed with anything that Mia said.

As they continued to write the supporting paragraph one about young people lacking self-control, they faced problem on how to conclude the paragraph.

\section{Excerpt 6}

837. M: Yes, their emotion, they always their

838. K: So, no, give us the last sentence about

839. L: yes

840. K: about the first, like

841. M: They always think

842. K: They should, they should control their self to be in this life

843. M: I think

844. K: This point lah

845. M: What?

846. K: Point new sentence, the last sentence

847. D: Last sentence

848. K: Maybe can be advise or maybe

851. M: What is the last sentence?

852. K: We must write the last sentence

853. M: This is the first is

854. K: They, they should control theirself because, to be in this life

855. D: Arr that is conclusion bah

856. M: What is your, what, what, what did you say, what did you say?

857. K: You know, you must write, you must write conclusion for-

858. D: So they should control

859. L: please

860. K: They should control themselves to be in this life

Mia initially forgot about writing the conclusion sentence for each paragraph. When Kamal pointed out that the concluding sentence could be an advice or suggestion, she again refused to accept his suggested concluding sentence. Kamal did not object as he resorted to just accept Mia's suggestion.

876. M: I think is mmm, so we, so the young people because they are not

877. D: So, I think, so we, we, we

878. L: Young people could not

879. M: Yeah, could not be consume, like this lah

880. K: It's ok

881. M: How?

882. D: I think

883. M: Don't say ok, its ok, you must

884. D: I think

885. K: Must what? I don't feel for you now, you must

886. D: I think before we

887. K: Write your feeling

888. M: Yeah, write my feeling

This is the stage when Kamal became more passive. Mia, on the other hand, pointed out that he could not merely agree with everything she said (line 883). Mia expected some comments from her group members. She insisted that her group members explained and gave feedback to which Kamal reacted by saying that he did not feel the same way as Mia since she always writes according to her feelings. Mia later wrote in her journal that she was angry and hurt by Kamal's words. She wanted to produce a good piece of writing which explained why she always questioned the others. On the other hand, Kamal mentioned in the interview that he felt it was useless for him to suggest anything because Mia always did not agree or accept his suggestion. Dee was frequently ignored (lines 877, 884, 886). She felt that her opinions were not significant. She wrote in her journal that she considered Mia and Kamal to be more knowledgeable and more proficient in English. 
In the final collaboration, the group had to deliberate again whether to agree or disagree with the topic: Celebrities are appropriate role models for young people. Excerpt 7 shows that there is a battle of the sexes where the female members disagree and the male members agree with the topic. The male members in the end avoided arguing with Mia and ended up taking the disagreeing stand.

\section{Excerpt 7}

92. L: Arr... because famous, arr many young people want to become successful, become a success man, so they want to study this famous people so

93. M: So you must follow their lifestyle, they

94. L: Yes

95. M: Everything about their life

96. K: Not must everything

97. L: But simple thing

98. K: yeah

\section{..}

103. M: This one says

104. D: This one says

105. M: err... you follow everything

106. $\mathrm{K}$ : What is the everything? (D and $\mathrm{M}$ sigh then all laugh)

107. D: Like err... the lifestyle arr or they behave good behave or bad behave

108. K: It's ok, disagree

109. D: Are you sure?

110. K: Yes (all laugh)

111. M: Are you sure?

112. K: It's ok, disagree, disagree

113. M: You can't receive my arguing

114. K: It's ok, disagree

This excerpt shows that Kamal and Liang in the end had to disagree with the topic although they initially agreed. Both the males and females had different interpretation about the topic. The excerpt shows that Mia was authoritative when she asked if they could not stand her argument. Apparently she was more interested in others following her than the other way round. Moreover, Kamal's response also showed that he knew Mia would not agree no matter what he said. Kamal could have contested Mia's ideas, but he decided to not do so and allowed Mia to take the lead.

Affective conflict had affected the group as the members began to show less commitment to the group. Doubts about other's capability also created dissatisfaction and reduced effort. It has caused an active group member to become passive. Although the group faced a high level of affective conflict, their main focus was to complete the writing task. This made them tolerate each other's behaviour by either agreeing completely with the more authoritative member or by ending the negotiation.

\section{Conclusion}

The findings reveal two types of conflicts that occurred in the collaboration. Substantive conflict encouraged the group members to think and debate extensively in their essay production. It also encouraged them to consider alternative word choices and supporting details. Nonetheless, the group experienced more affective conflict due to members doubting each other and lacked of sense of belonging. Being ignored was also one of the factors that caused affective conflict. Since the group's focus was to complete their task, they chose to tolerate one another. Although conflict can enhance cognitive processes, it can be detrimental if it is not addressed appropriately where a member began to become more passive due to affective conflict. The study also shows that it is important that students are encouraged to express their thoughts explicitly instead of assuming their members to know what is in their mind to avoid misunderstanding, or doubts among group members (Gimenez $\&$ Thondhlana, 2012).

The study indicates that students do benefit from collaborative writing and through appropriate conflict resolution they are able to reconsider alternatives and reach consensus. High levels of affective conflict among group members, on the other hand, caused group dissatisfaction. A number of recommendations can be drawn for future practice. Writing instructors should be aware of the conflict that their students may face during collaborative writing and demonstrate negotiation skills. Besides that, writing instructors should facilitate when

\footnotetext{
Page $\mid 16$ 
International Journal of Applied Linguistics \& English Literature

ISSN 2200-3592 (Print), ISSN 2200-3452 (Online)

Vol. 1 No. 7; November 2012 [Special Issue on Applied Linguistics]

necessary to encourage passive member to contribute to the group. From students' reflections, teachers can intervene by encouraging members to be more open about how they feel or to establish group rules.

From the above recommendations, writing instructors should encourage collaborative writing although conflict may be inevitable. As the study shows, conflict does have positive outcome. Collaborative writing is a useful method in ESL/EFL writing classes because it develops teamwork, provides a socially rich situation where the novice can learn from a more capable person. Besides, students also practise the target language during their collaborative writing session which improves their proficiency and develops their confidence to use the target language. It also inculcates team spirit which promotes interpersonal communication and conflict management that is applicable in the work place where teamwork is highly valued.

\section{References}

Aljaafreh, A., \& Lantolf, J. P. (1994). Negative feedback as regulation and second language learning in the zone of proximal development. Modern Language Journal, 78, 465-483.

Amason, A.C. (1996). Distinguishing the effect of functional and dysfunctional conflict on strategic decision making: Resolving a paradox for top management teams. Academy of Management Journal, 39(1), 123-148.

Barron, B. (2003).When smart groups fail. Journal of Learning Science, 12(3), 307-359.

Bruffee, K. A. (1973). Collaborative learning: Some practical models. College English, 34, 634-643.

http://dx.doi.org/ 10.2307/375331

Bruner, J. S. (1975). The ontogenesis of speech acts. Journal of Child Language, 2, 1-19.

Burnett, R.E. (1993). Conflict in collaborative decision-making. In N.R. Blyler \& C. Thralls (Eds.), Professional communication: The social perspective (pp. 144-163). Newbury Park, CA: Sage.

Carson, J., \& Nelson, G. (1996). Chinese students' perceptions of ESL peer response group interaction. Journal of Second Language Writing, 5(1), 1-19.

Dale, H. (1994). Collaborative writing interactions in one ninth-grade classroom. Journal of Educational Research, 87 (6), 334-344.

Derry, S. J. (1992). Beyond symbolic processing: expanding horizons for educational psychology. Journal of Educational Psychology, 84, 413-418.

Ede, L., \& Lunsford, A. (1985). Let them write- together. English Quarterly, 18(4), 119-127.

Eisenhardt, K. M., Kahwajy, J. L., \& Bourgeois, L. J. (1997). How teams have a good fight. Harvard Business Review, 75(4), 77-86.

Gimenez, J., \& Thondhlana, J. (2012). Collaborative writing in engineering: Perspectives from research and implications for undergraduate education. European Journal of Engineering Education, 1-17.

Hilgers, T. (1987). Young writers facing a new collaborative writing task. Journal of Research in Childhood Education. 2 (2), 108-116. doi: 10.1080/02568548709594927

Hofstede, G. (1980). Culture's Consequences: International differences in work related values. (2 ${ }^{\text {nd }}$ ed.). Beverly Hill, CA: Sage.

Jehn, K. A. (1995). A multimethod examination of the benefits and detriments of intragroup conflict. Administrative Science Quarterly, 40, 256-282.

Krause, S. D. (2007). The process of research writing chapter four, "How to collaborate and write with others". Retrieved May 2, 2011 from the Process of Research Writing Web site: http://www.stevendkrause.com/tprw/

Lee, M. (2011). Decision making in a collaborative writing task. Proceedings of the 3rd CELC Symposium, National University of Singapore, 159-168.

Liao, M. Y. (2007). Losing face in Chinese and American culture: Precursors and consequences. Papers from the Second International Conference on Multicultural Discourses, Hangzhou, China.

Luca, J., \& Tarricone, P. (2001). Does emotional intelligence affect successful teamwork? Proceedings of the 18th Annual Conference of the Australasian Society for Computers in Learning in Tertiary Education, Melbourne: University of Melbourne, 367- 376. 
International Journal of Applied Linguistics \& English Literature

ISSN 2200-3592 (Print), ISSN 2200-3452 (Online)

Vol. 1 No. 7; November 2012 [Special Issue on Applied Linguistics]

Putnam, L. (1986). Conflict in group decision making. In Hirokawa, R.Y. and Poole, M.S. (Eds.), Communication and group decision making (pp. 175-96). Beverly Hills, CA: Sage.

Seo, H. S., \& Kim, T. Y. (2011). Collaborative dialogues and L2 learning: Korean junior high school students' pair-work in English composition. Korean Journal of Applied Linguistics, 27(1), 345-380.

Shantz, C. U. (1987). Conflicts between children. Child Development, 58, 283-305.

Stewart, D. (1988). Collaborative learning and composition: boon or bane? Rhetoric Review, 7(1), 58-83.

Storch, N. (2002). Patterns of interaction in ESL pair work. Language Learning, 52, 119-158.

Storch, N. (2005). Collaborative writing: Product, process and students' reflections. Journal of Second Language Writing, 14(3), 153-173.

Storch, N. (2011). Collaborative writing in L2 contexts: processes, outcomes, and future directions. Annual Review of Applied Linguistics, 31(1), 275-288. doi: 10.1017/S0267190511000079

Strauss, P. (2001). "I'd rather vomit up a live hedgehog"- L2 students and group assessment in mainstream university programs. Prospect, 16, 55-66.

Tocalli-Beller, A. (2003). Cognitive conflict, disagreement and repetition in collaborative groups: Affective andsocial dimensions from an insider's perspective. The Canadian Modern Language Review, 60(2), 143-71.

Trimbur, J. (1989). Consensus and difference in collaborative learning. College English, 51(6), 602-616.

Yong M. F. (2010). Collaborative writing features. RELC Journal, 41(1), 18-30.

Yong, M. F. (2011). Improving ESL learners' academic text construction through a collaborative task. Pertanika Journal of Social Science \& Humanities, 19(2), 475-485.

Villamil, O.S., \& de Guerrero, M.C.M. (1996). Peer revision in the L2 classroom: Social-cognitive activities, mediating strategies, and aspects of social behavior. Journal of Second Language Writing, 5(1), 51-75.

Villamil, O. S., \& de Guerrero, M. C. M. (1998). Assessing the impact of peer revision in L2 writing. Applied Linguistics, 19(4), 491-514.

Vygotsky, L. S. (1978). Mind in society: The development of higher psychological processes. Cambridge, MA: Harvard University Press. 